\title{
Recovery of Gallium, Indium and Arsenic from Semiconductors using Tribromide Ionic Liquids
}

Arne Van den Bossche ${ }^{\dagger}$, Willem Vereycken ${ }^{\dagger}$, Tom Vander Hoogerstraete $^{+}$, Wim Dehaen $^{+}$ and Koen Binnemans ${ }^{\dagger *}$

† KU Leuven: Department of Chemistry, Celestijnenlaan 200F, P.O. box 2404, Heverlee, B-3001, Belgium Corresponding author: Prof. Koen Binnemans E-mail: Koen.Binnemans@kuleuven.be

A. Van den Bossche, W. Vereycken, T. Vander Hoogerstraete, W. Dehaen, K. Binnemans ACS Sustainable Chemistry \& Engineering 7, 14451-14459 (2019).

DOI: 10.1021/acssuschemeng.9b01724 


\begin{abstract}
The leaching of semiconductors (GaN, GaAs and InAs) and LEDs in a nonvolatile tribromide ionic liquid and the selective recovery of gallium, indium and arsenic from this ionic liquid was investigated. In order to prevent the formation of the highly toxic arsine $\left(\mathrm{AsH}_{3}\right)$, usually formed when leaching metal arsenides with acids, the hydrophobic trihalide ionic liquid tributyldecylphosphonium tribromide $\left[\mathrm{P}_{44410}\right]\left[\mathrm{Br}_{3}\right]$ was used to oxidatively leach the semiconductors, avoiding arsine formation. After leaching, a selective stripping procedure was applied to remove and recover the arsenic, gallium and indium. Arsenic and gallium could be stripped using $\mathrm{NaBr}$ solutions and pure water respectively, while indium was removed from the ionic liquid phase via precipitation stripping with a $\mathrm{NaOH}$ solution. A mechanistic study was performed to explain this difference in stripping behavior. A flowsheet was proposed and finally, the procedure was applied to real LEDs.
\end{abstract}

Keywords: critical raw materials; ionic liquids; polyhalides; recycling; solvometallurgy 


\section{Introduction}

Light emitting diodes (LEDs) are increasingly popular light sources. ${ }^{1,2}$ They have many advantages, including a high energy efficiency, a long lifetime, and the absence of toxic mercury. Although LEDs are still a recent lighting technology, it is of importance to develop recycling technology for end-of-life LEDs before large volumes of this waste stream will become available. Two metals that are particularly relevant to LED recycling are gallium and indium. Gallium is currently produced as a byproduct of alumina production from bauxite. Indium is obtained as a byproduct of primary zinc production. End-oflife LEDs could prove to be an interesting alternative source of gallium and indium as they are present in the used semiconductors as the main components, instead of trace elements. ${ }^{3}$ Despite LEDs being a valuable secondary source for gallium and indium, there are still no straightforward recycling routes. ${ }^{4}$ Recycling of LEDs is challenging, because they are often incorporated in larger devices which are difficult to dismantle. Additionally, the semiconductors in the LEDs are embedded in a plastic casing which has to be removed. ${ }^{5}$ Some research on the recycling of GaN, GaAs and InAs semiconductors, the main active compounds in LEDs, has been performed. Zhang et al. reported several procedures contributing to the recycling of semiconductors, including the separation of gallium, indium and thallium from aqueous chloride solutions by solvent extraction using acid extractants and the sulfurizing thermal treatment of GaAs. ${ }^{6,7}$ Nagy et al. used a combination of mechanochemical activation by $\mathrm{Na}_{2} \mathrm{CO}_{3}$ and thermal treatment at $1200{ }^{\circ} \mathrm{C}$ to recover gallium from GaN semiconductors. ${ }^{5}$ Swain et al. reported similar procedures for the recycling of GaN in waste dust from the LED industry, using mechanochemical activation, followed by thermal processing at $1100{ }^{\circ} \mathrm{C} .{ }^{8}$ Although these thermal processes are effective, the cost and safety risks associated with high temperatures and strong acids are substantial. The development of a process at ambient temperatures would be beneficial. This was achieved by Hu et al., who leached GaAs using nitric acid solutions, followed by a selective precipitation of arsenic from these solutions. ${ }^{9}$ 
The formation of arsine $\left(\mathrm{AsH}_{3}\right)$ gas is a significant safety issue during dissolution of arsenic-containing semiconductors. Arsine is ranked among the most dangerous arsenic compounds, mainly due to its volatility. A concentration of $10 \mathrm{ppm}$ in air can already be lethal. As a heavy, colorless gas that has a toxicity threshold lower than its odor detection limit, it was even considered as a chemical warfare agent. ${ }^{10}$ Arsine is formed by reaction between arsenic and hydrogen gas, or when metallic arsenides are dissolved in solutions of strong acids. ${ }^{11}$ Most incidents in industry originate from the treatment of arsenic-containing materials with concentrated acids, particularly hydrochloric acid. ${ }^{10}$ Taking into account that much of the research on the recycling of semiconductor waste is performed using aqueous acids, it would be highly beneficial to investigate safer processes for the dissolution of metal arsenides without the use of aqueous solutions and acids. ${ }^{6,9}$ Solvometallurgy could provide an interesting alternative to aqueous conditions used in traditional hydrometallurgy. ${ }^{12}$ Solvometallurgy is an emerging field of extractive metallurgy that uses nonaqueous solvents at ambient conditions. Its advantages include the elimination of waste water and different selectivities compared to aqueous systems, as well as the lower temperatures of processes. ${ }^{12}$ Ionometallurgy is a subdivision of solvometallurgy, that uses ionic liquids as solvents. ${ }^{13}$ Ionic liquids (ILS) are solvents that are composed solely of ions, and as a consequence, their vapor pressure is extremely low. ${ }^{14,15}$ This makes them nonvolatile solvents at ambient conditions, a major advantage over volatile organic solvents often used in industry. Their ionic character also implies intrinsic conductivity, which prevents electrostatic charge buildup and potentially hazardous sparking in industrial solvent extraction operations. ${ }^{16,17}$ These two properties, nonvolatility and the absence of electrostatic charge buildup, enhance process safety significantly by reducing the risk of fires and explosions. The main disadvantages of ILs, however, are their high cost and high viscosity, especially at ambient temperatures.

In this paper, trihalide ionic liquids will be used for the leaching and recycling of semiconductors. This special group of ionic liquids contain an anion that is composed of a bound cluster of halogen atoms 
bearing a negative charge smaller than the total number of halogen atoms present in the anion. ${ }^{18-20}$ Therefore, they show a strong tendency to take up electrons, but have a negligible vapor pressure since they are ILs. ${ }^{21,22}$ These trihalide ILs can thus be regarded as halogen carriers with negligible vapor pressure, in contrast to other halogen carries, such as bromine-methanol, that are aggressive and volatile solutions. ${ }^{23-27}$ This makes trihalide ILs useful as oxidizing agents for organic and metallic compounds, while enhancing process safety. ${ }^{28-32}$ They are capable of dissolving both metals and alloys without the formation of any gases, as shown in previous research. ${ }^{21,33-36} \mathrm{In}$ this paper, the dissolution of $\mathrm{GaN}, \mathrm{GaAs}$ and InAs in tribromide ILs and the selective recovery of gallium, indium and arsenic from this IL are investigated. Most experiments are carried out with the ionic liquid tributyldecylphosphonium bromide, $\left[\mathrm{P}_{44410}\right]\left[\mathrm{Br}_{3}\right]$. Besides the pure semiconductor compounds, real LEDs are investigated as well.

\section{Experimental}

\section{Chemicals and equipment}

See Supporting Information

\section{Leaching of semiconductors}

Prior to leaching, the samples were ground using a mortar and pestle. The powder was sieved and separated in three different fractions: $<63 \mu \mathrm{m},>125 \mu \mathrm{m}$ and between 63 and $125 \mu \mathrm{m}$. The semiconductors (GaAs, InAs and GaN) were mixed with tribromide IL in a 1:10 molar ratio in $20 \mathrm{~mL}$ glass vials. Cylindrical aluminum blocks were used for controlled heating of these vials. The vials were shielded from light during leaching to prevent photodecomposition of the IL. The solutions were heated to $60^{\circ} \mathrm{C}$ and stirred at $200 \mathrm{rpm}$ for the total duration of the dissolution experiments, unless stated otherwise. 
A synthetic leachate solution of semiconductor materials InAs and GaAs in tribromide IL was prepared for later stripping experiments. This synthetic solution was based on the composition of the leachate obtained after the leaching of an equimolar mixture of $\mathrm{GaAs}$ and $\operatorname{InAs}$ with the ionic liquid $\left[\mathrm{P}_{44410}\right]\left[\mathrm{Br}_{3}\right]$ in in a molar ratio of GaAs/InAs/[P $\left.\mathrm{P}_{44410}\right]\left[\mathrm{Br}_{3}\right]$ of 1:1:20. The metal content of this leachate was $7.5 \mathrm{~g} \mathrm{~L}^{-1}$ gallium, $12.5 \mathrm{~g} \mathrm{~L}^{-1}$ indium and $16 \mathrm{~g} \mathrm{~L}^{-1}$ arsenic. This leachate is hereafter referred to as 'mixed leachate' and was used in the majority of stripping experiments, unless stated otherwise.

\section{Stripping}

Stripping experiments were performed in $4 \mathrm{~mL}$ glass vials. The samples were shaken at $2000 \mathrm{rpm}$ at $60{ }^{\circ} \mathrm{C}$ for $1 \mathrm{~h}$. After mixing, the samples were centrifuged at $4500 \mathrm{rpm}$ for $3 \mathrm{~min}$. Unless stated otherwise, the volume ratio was kept at 1:1. When determining the stripping percentages, the metal concentrations of either the IL, $n$-dodecane or the aqueous phase were measured. However, the stripping percentage was always calculated as the percentage of the metals that moved from the original phase to the phase it was contacted with, regardless of the polarity of the phase, as this is not always the same direction. When the distribution ratio (D) of a certain metal is reported, it is always the ratio of amount of metal in the ionic liquid phase $\left(\mathrm{C}_{\mathrm{M}, \mathrm{LL}}\right)$ over the amount of metal in the strip solution $\left(C_{M, s t r}\right)$, no matter the polarity (Equation 1$)$.

$$
D=\frac{\mathrm{C}_{\mathrm{M}, \mathrm{IL}}}{\mathrm{C}_{\mathrm{M}, \mathrm{str}}}
$$

\section{Results and discussion}

\section{Screening of ionic liquids}

Since the main objective of this research is the safe dissolution of semiconductors in tribromide ILs and their removal, stripping, from these ILs, the phases used for stripping should be compatible with the used ILs. Two important factors are the stability of the ILs and the possible loss of IL after mixing and 
phase separation. Two green solvents were used in the stripping studies: water (polar) and $n$-dodecane (apolar). An IL that is compatible with both solvents is required for dissolving the semiconductors. Even though the tribromide IL would be used for real leaching experiments, the corresponding (mono)bromide ILs were tested for the solubility studies. This approach was adopted since the reduction of the tribromide will result in the formation of a bromide IL. These are more hydrophilic compared to tribromide, so testing the latter could result in underestimation of the losses cause by solvent extraction. Besides that, the bromide ILs are readily available, without the need for conversion into the tribromide ILs. All the bromide ILs tested are summarized in Table S2. Solid ILs were considered since they might become liquid phases after mixing with water or $n$-dodecane. The two most promising ILs, $\left[\mathrm{P}_{44410}\right] \mathrm{Br}$ and [EMIM] $\mathrm{Br}$, were investigated with $n$-dodecane phases loaded with extractants. Three extractants were chosen that are used to extract indium (Figure 1). Extractants with unsaturated carbon bonds were discarded, as these are brominated by the tribromide IL. ${ }^{19,29,37-39}$ 


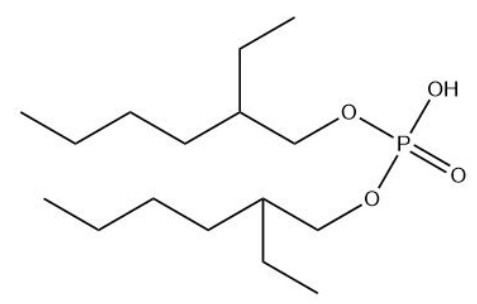

D2EHPA

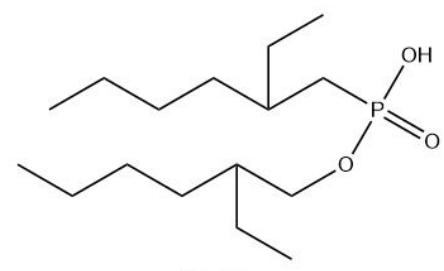

PC-88a

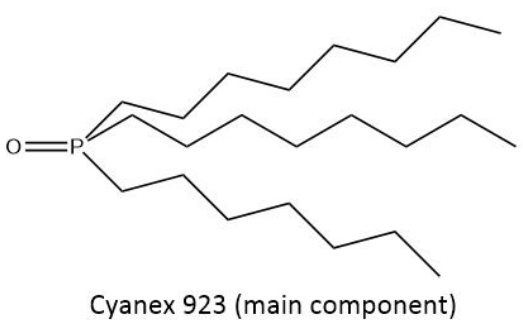

Figure 1: Extractants used in this study and their chemical structure.

From the conducted solubility experiments (Table $\mathrm{S} 2$ and Table $\mathrm{S} 3$ ) it was concluded that $\left[\mathrm{P}_{44410}\right][\mathrm{Br}]$ was the best candidate for further dissolution and separation experiments due to its liquid state and low miscibility with water and $n$-dodecane. $\left[\mathrm{P}_{66614}\right] \mathrm{Br}$ and $[\mathrm{EMIM}] \mathrm{Br}$ were also liquid after mixing with $n$ dodecane but the former showed unacceptably high solubility in the $n$-dodecane phase, and the latter is miscible with water. For the IL of choice $\left(\left[\mathrm{P}_{44410}\right][\mathrm{Br}]\right)$ and its tribromide analog, the potential loss to the water phase upon mixing was tested by ${ }^{31} \mathrm{P}$ NMR spectroscopy, but neither the bromide or tribromide IL exhibited any losses to the aqueous phase (Figure S2 and S3). Additionally the water uptake of $\left[\mathrm{P}_{44410}\right]\left[\mathrm{Br}_{3}\right]$ was measured: $1.22 \mathrm{wt} \%$ (Figure $\mathrm{S} 1$ ), which is significantly lower compared to the bromide IL: $16.7 \mathrm{wt} \%$. This decreased solubility originates from the higher hydrophobicity of the tribromide anion. Furthermore, the stability of the tribromide anion upon mixing with water was determined using 
Raman spectroscopy. Over a period of 72 hours, equal masses of water and $\left[\mathrm{P}_{44410}\right]\left[\mathrm{Br}_{3}\right]$ were mixed at $60{ }^{\circ} \mathrm{C}$, the cation and tribromide anion signals were compared. During the entire measurement, no loss of tribromide anion was observed (Figure S4).

\section{Dissolution rate}

In a first experiment, the three semiconductors GaAs, InAs and $\mathrm{GaN}$ were roughly ground into grains of about $2 \mathrm{~mm}$ in diameter. Each semiconductor was added to $\left[\mathrm{P}_{44410}\right]\left[\mathrm{Br}_{3}\right]$ in a molar ratio of $1: 10$, and stirred for $48 \mathrm{~h}$ at $60^{\circ} \mathrm{C}$ in closed vials. Afterwards, the mixtures were filtered to determine the dissolution of the semiconductors. The solutions of GaAs and InAs showed signs of oxidative dissolution: the particle size decreased and the IL darkened in colored and increased in viscosity, indicating metal dissolution into the IL. The GaN sample, however, showed none of these signs, and the particles did not dissolve. It has already been reported that harsh conditions are required to dissolve GaN, which is a very hard material with a Wurzite crystal structure ${ }^{40}$ For example, GaN dissolves at reasonable rates in wet $\mathrm{KOH}$ and $\mathrm{NaOH}$ at $250{ }^{\circ} \mathrm{C} .{ }^{41}$ It was thought that the strongly oxidizing ILs used in this work, which are also capable of dissolving gold, might dissolve the GaN, but this was revealed to be not the case. A possible explanation for the different behavior of GaN compared to GaAs in the reaction with tribromide anions, is that in order to release the gallium, its counter atom should be able to react with bromide anions. Arsenic, in contrast to nitrogen, can readily form bromide salts.

The leaching rates of GaAs and InAs in $\left[\mathrm{P}_{44410}\right]\left[\mathrm{Br}_{3}\right]$ were studied further by periodically measuring the metal content in the IL. The GaAs and InAs were ground and sieved and the fraction between 63 and 125 $\mu \mathrm{m}$ was used. The samples were prepared as described in the experimental section, but were stirred at $300 \mathrm{rpm}$ and at room temperature. The IL samples were digested using a microwave digester and the metal content was measured using ICP-OES. The results are displayed in Figure 2. 


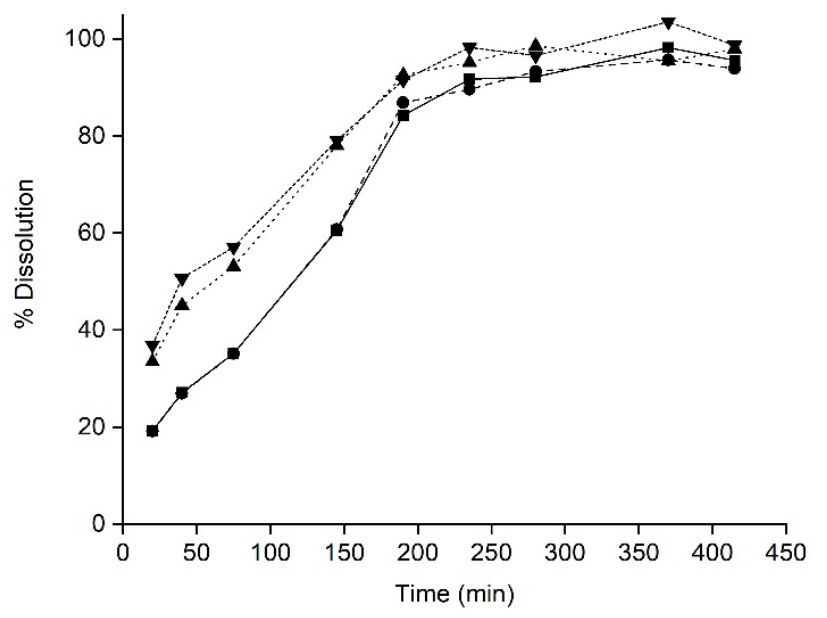

Figure 2: Dissolution of GaAs and InAs particles (63-125 $\mu \mathrm{m})$ in $\left[\mathrm{P}_{44410}\right]\left[\mathrm{Br}_{3}\right]$ at $R T$ as a function of time; $\bullet \mathrm{Ga}$ and $\boldsymbol{\|}$ As (GaAs), $\boldsymbol{\nabla}$ In and $\mathbf{\Delta}$ As (InAs). Molar ratio semiconductor-to-IL 1:10.

Both GaAs and InAs dissolved at similar rates, which stagnated after about 200 min due to the completion of the reaction (Figure 2). Indium arsenide seems to dissolve slightly faster compared to gallium arsenide, a possible explanation might be the cohesive energy, a measure of how much energy is required to separate the material into atoms. This energy is higher for GaAs (1.63 eV) compared to InAs $(1.55 \mathrm{eV}) .{ }^{42}$ The most important conclusion, however, is that both semiconductors were completely dissolved by the IL, albeit not at the same rate, yielding a homogeneous solution of metals in $\left[\mathrm{P}_{44410}\right]\left[\mathrm{Br}_{3}\right]$.

\section{Stripping of Ga and As}

In order to obtain pure fractions of gallium, indium and arsenic, a selective stripping procedure for these elements was developed, with the objective of achieving both a high purity and a high recovery of the fractions. In order to minimize the risk of arsine formation, it was investigated if aqueous conditions could be avoided altogether, not just in the leaching step. The use of $n$-dodecane phases containing various extractants for the selective stripping of arsenic, gallium and indium was investigated. 
(Figure S5). The stripping proved troublesome as the elements were stripped with low yields of less than $23 \%$ and almost no selectivity for any of the three metals.

As an alternative, the selective stripping of the metals with aqueous solutions was investigated. Indium is difficult to remove from IL phases using aqueous solutions, as shown in previous research. ${ }^{43}$ Thus, the first goal was to find a selective stripping process for arsenic and gallium by contacting the loaded IL with different stripping solutions. The equilibrium between the metal in the IL and the free metal ions in the aqueous solution (Equation 2), can be shifted by adjusting the bromide concentration or by adding a complexing agent to the aqueous solution:

$$
\mathrm{M}^{3+}+3 \mathrm{Br}^{-}+\left[\mathrm{P}_{44410}\right][\mathrm{Br}] \leftrightarrows\left[\mathrm{P}_{44410}\right]\left[\mathrm{MBr}_{4}\right]
$$

Several solutions were tested, namely pure water, different concentrations of hydrobromic acid, a solution of the polydentate citrate ligand, and a sodium sulfate solution. The latter was considered since sulfate is known to be a strongly coordinating anion. Hydrobromic acid proved the best species for stripping the metals with various selectivities (Figure 3). 


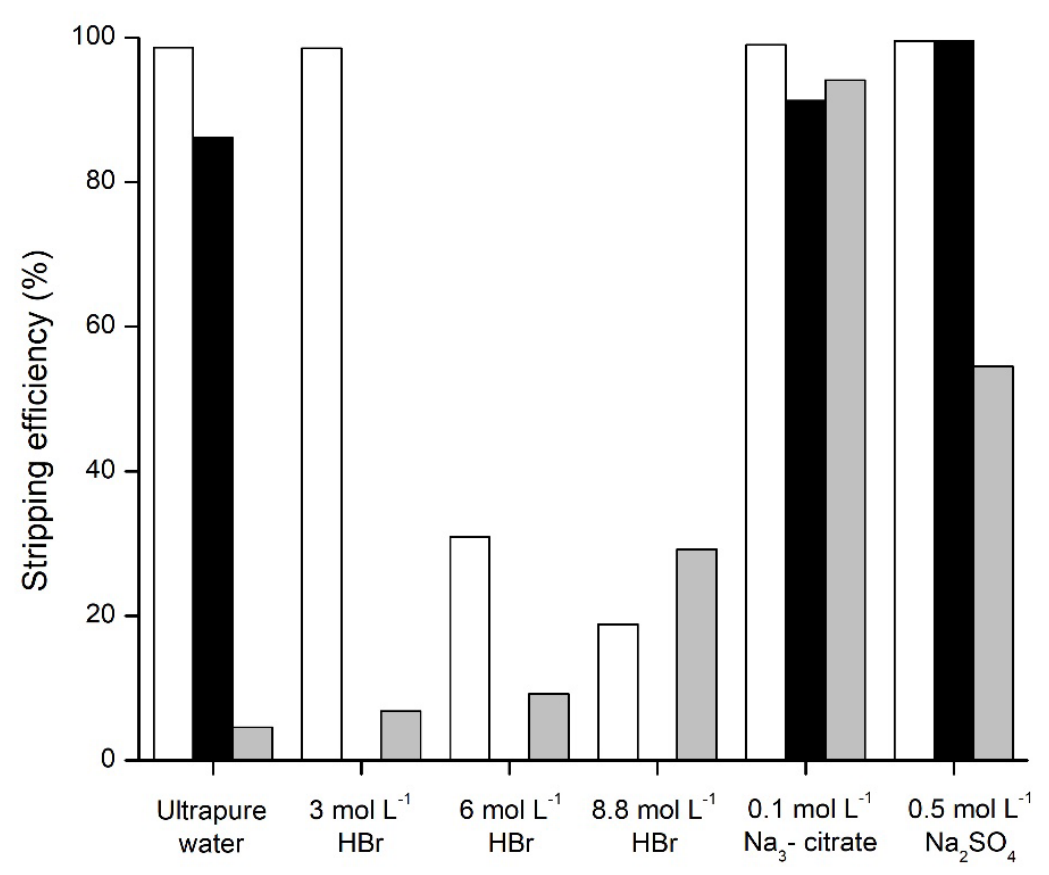

Figure 3: Stripping efficiencies (\%) of arsenic ( $\square$ ), gallium ( $\square$ ) and indium ( $\square$ ) from loaded $\left[\mathrm{P}_{44410}\right]\left[\mathrm{Br}_{3}\right]$ with initial concentrations of $16.0 \mathrm{~g} \mathrm{~L}^{-1} \mathrm{As}, 7.5 \mathrm{~g} \mathrm{~L}^{-1} \mathrm{Ga}$ and $12.5 \mathrm{~g} \mathrm{~L}^{-1} \mathrm{In}$.

The cheaper chloride anion could arguably be preferred over bromide for both the synthesis of a trihalide IL and for controlling the stripping with aqueous phases. However, the synthesis of tribromide ILs is much safer and more convenient due to the liquid state of bromine compared to the gaseous chlorine. The stripping with chloride solutions was not investigated as this could result in an anion exchange, resulting in a chloride IL. This effect is limited since the bromide anion is placed higher than chloride in the Hofmeister series, but might not be negligible as they are placed close to each other. The potential risk of contaminating the IL and/or bromide streams, was eliminated by avoiding chloride solutions.

With this information, the effect of consecutive stripping of the same IL phase with various aqueous phases was investigated by designing two sets of stripping procedures consisting of six steps. The first three steps are washing steps with a $2 \mathrm{~mol} \mathrm{~L}^{-1} \mathrm{NaBr}$ solution, used as an alternative for the strongly acidic $\mathrm{HBr}$, to selectively recover arsenic from the loaded IL. The last three washing steps were either pure water 
or a $2 \mathrm{~mol} \mathrm{~L}^{-1}$ solution of $\mathrm{Na}_{2} \mathrm{SO}_{4}$ to subsequently remove gallium from the loaded IL. The stripping tests were performed on two identical samples of mixed leachate, and the O:A ratio was kept at 1 for both solutions. The results of the stripping efficiencies of each step are shown in Figure 4.
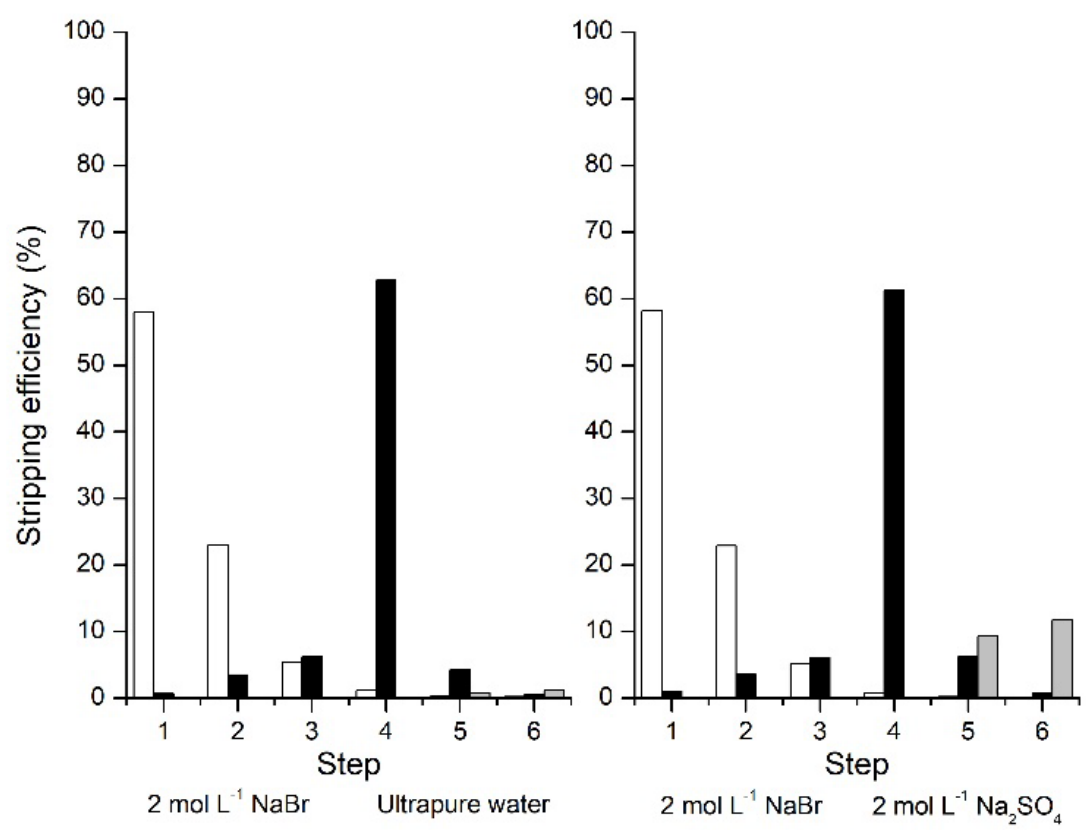

Figure 4: Stripping efficiencies (\%) of arsenic ( $\square$ ) gallium ( $\square$ ) and indium ( $\square$ ) of consecutive stripping solutions from mixed leachate solutions. Initial IL concentrations of $16.0 \mathrm{~g} \mathrm{~L}^{-1} \mathrm{As}, 7.5 \mathrm{~g} \mathrm{~L}^{-1} \mathrm{Ga}$ and $12.5 \mathrm{~g} \mathrm{~L}^{-1}$ In $60{ }^{\circ} \mathrm{C}, 200 \mathrm{rpm}, 0: \mathrm{A}$ ratio $=1$

The results in Figure 4 showed that the sulfate anion, despite being an efficient coordinating anion, is not preferred as it promotes the stripping of indium from the IL, therefore contaminating the galliumenriched solution. If the $\mathrm{NaBr}$-water system is used, the stripping of indium is inhibited and the collected gallium fraction has a higher purity ( $99 \%$ gallium). For this reason the $\mathrm{NaBr}$-water procedure was chosen as the ideal solution for the selective removal of arsenic and gallium from the tribromide IL.

The stripping steps with the $\mathrm{NaBr}$ solution were further optimized with regard to the exact concentration and the O:A ratio, in order to increase the purity and recovery of arsenic and gallium. The fifth and sixth step were discarded as they showed to only have a limited effect on the stripping. As in the experiments described above (Figure 4), the first three steps were performed with aqueous $\mathrm{NaBr}$ 
solutions, the fourth step with pure water. During these first three steps, different concentrations of $\mathrm{NaBr}$ were used and the volume ratio of the phases was varied (Figure 5).

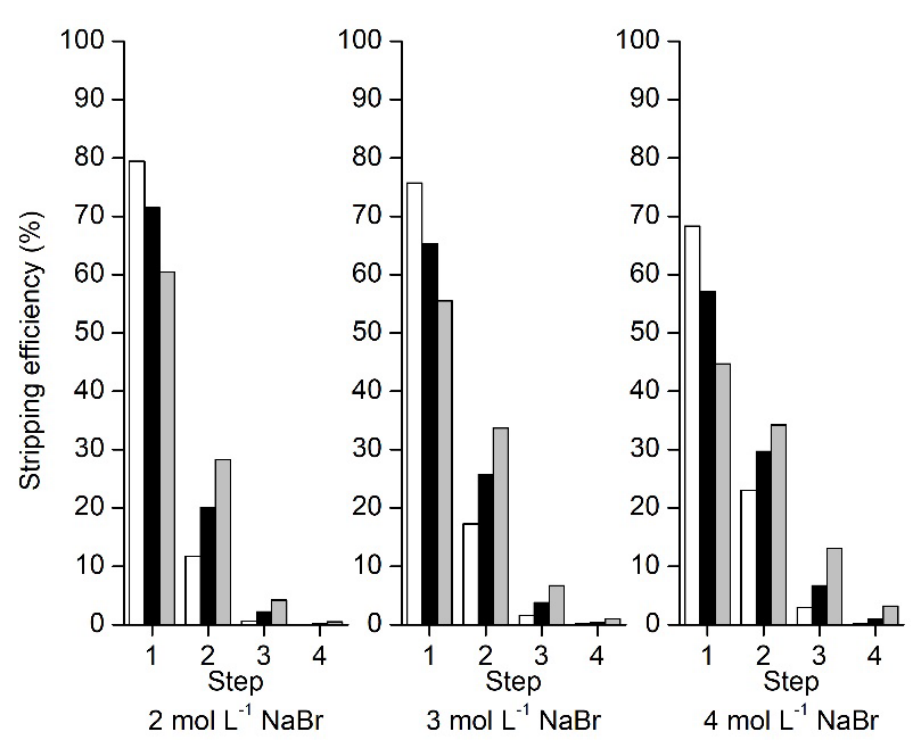

Figure 5: Stripping of arsenic (16.0 $\left.\mathrm{g} \mathrm{L}^{-1}\right)$ from mixed leachate solutions, with varying $\mathrm{NaBr}$ concentration and O:A ratio: 1 ( $\left.\square\right)$, 1.5 (घ) and 2 ( $\square$ ). Step 1-3: NaBr solution, step 4: pure water.

The stripping of arsenic was enhanced when using lower concentrations and lower O:A ratios. However, the effect after multiple steps remained similar (Figure 5). In practice this means that no matter which of these conditions are chosen, the total amount of recovered arsenic after three steps remains the same (94\%). It would therefore be better to investigate the effect of these parameters on the subsequent stripping of gallium, which appears to be significantly influenced by the conditions used for the first three steps (Figure 6). Even though the efficiencies vary only a couple percentages, the loss of gallium should be avoided, not only to increase recovery but also to keep the arsenic fraction as pure as possible. The influence of the $\mathrm{NaBr}$ concentration seems to have the largest effect, although the O:A ratio is also important. Thus, both parameters should be set at a high value in order to suppress the stripping of gallium along with arsenic. It is obvious that using a larger O:A ratio decreases the stripping 
of both metals, as there is less strip solution. Increasing the bromide concentration suppresses the stripping of gallium. This is due to the release of bromide to the aqueous phase accompanied with the transfer of gallium. Therefore, increasing the original bromide concentration in the aqueous phase suppresses the gallium stripping (vide infra).

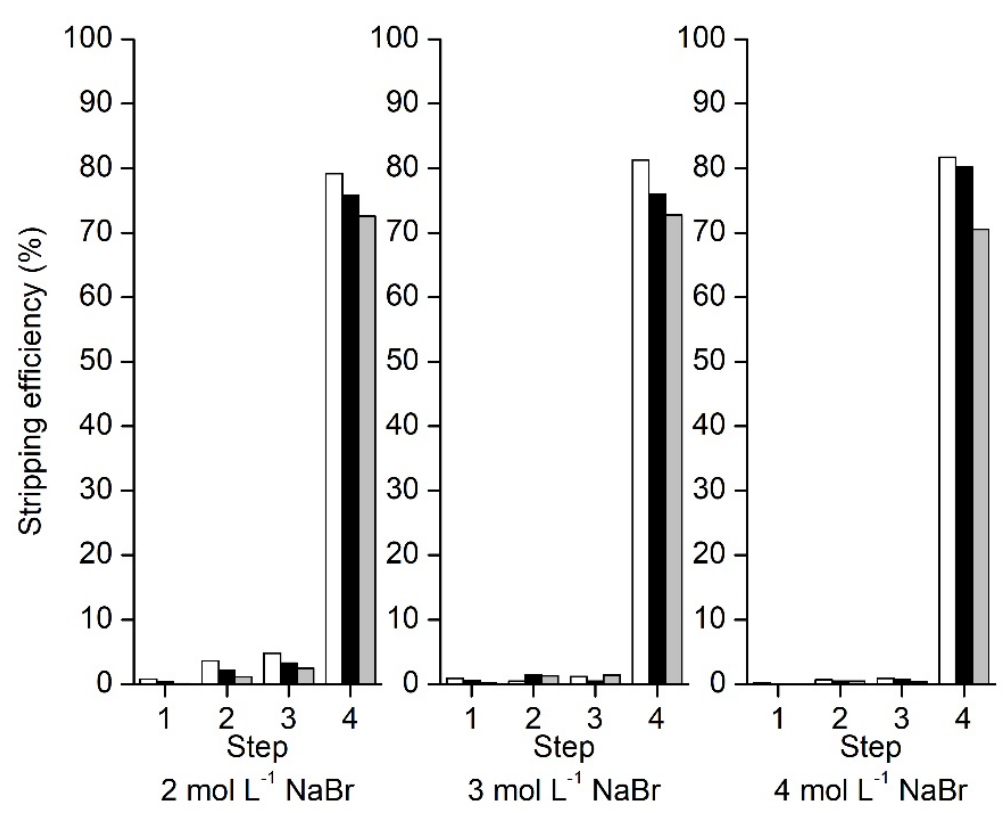

Figure 6: Stripping of gallium (7.5 $\left.\mathrm{g} \mathrm{L}^{-1}\right)$ from loaded tribromide IL, with varying NaBr concentrations and O:A ratio: 1 ( $\square$ ), 1.5 ( $\square$ ) and 2 ( $\square$ ). Step 1-3: NaBr solution, step 4: pure water.

In conclusion, an aqueous solution of $4 \mathrm{~mol} \mathrm{~L}^{-1} \mathrm{NaBr}$ can be applied to quantitatively strip arsenic from the mixed leachate in three steps. If the O:A was kept at 2, the stripping of gallium along with arsenic is limited to less than $1 \%$. The gallium can be stripped at a later stage using pure water with a lower O:A ratio (more water), to ensure quantitative gallium removal. Using three washing steps removes $96 \%$ of the gallium from the IL. The indium remains in the IL during the entirety of the arsenic and gallium removal, to be quantitatively removed afterwards, leaving the ionic liquid available for recycling. 


\section{Precipitation stripping of indium}

In the previous paragraphs, the removal of arsenic and gallium was investigated, but indium was not stripped and remained in the loaded tribromide IL leachate (Figure 4). Alkaline precipitation stripping was tested to remove indium. In previous work by Deferm et al., indium was stripped from the phosphonium chloride IL: Cyphos IL 101, by contacting the IL with a solution of $\mathrm{NaOH}$ (Equation 3). ${ }^{43}$ This caused the indium to form $\ln (\mathrm{OH})_{3}$, insoluble in both the IL and the aqueous phase. The precipitated $\ln (\mathrm{OH})_{3}$ could be filtered off (Equation 3):

$$
\left[\mathrm{P}_{44410}\right]\left[\operatorname{InBr}_{4}\right]+3 \mathrm{NaOH} \leftrightarrows \ln (\mathrm{OH})_{3, \mathrm{~S}}+3 \mathrm{NaBr}_{\mathrm{aq}}+\left[\mathrm{P}_{44410}\right][\mathrm{Br}]
$$

$\ln (\mathrm{OH})_{3}$ precipitates and the formed $\mathrm{NaBr}$ is transferred to the aqueous phase, leaving the phosphonium bromide IL behind. The position of this equilibrium can be influenced by adjusting the $\mathrm{pH}$ of the strip solution, as increasing the $\mathrm{pH}$ will result in more stripping of indium. An optimum has to be found between good stripping efficiencies and preventing decomposition of the IL in the process, as hydroxide could react with the cation to form phosphine oxides. ${ }^{43-45}$ The stability of the IL in contact with solutions of $\mathrm{NaOH}$ was investigated by mixing the phases and analyzing the amount of phosphine oxide present using ${ }^{31} \mathrm{P}$ NMR. It was found that at room temperature, the standard stripping experiments, as described in the experimental section, could be performed with solutions of up to $1.3 \mathrm{~mol} \mathrm{~L}^{-1} \mathrm{NaOH}$ without any decomposition of the IL.

The stripping experiments were performed on synthetic IL leachates, containing $25 \mathrm{~g} \mathrm{~L}^{-1}$ of indium, as this is the amount that would remain if arsenic is removed from pure InAs leachate solutions. A series of experiments at different stripping conditions was performed (Table 1). The O:A ratio was decreased to use less concentrated solutions, which prevents the decomposition of the IL. 
Table 1: Efficiencies for stripping indium from a synthetic loaded IL $\left(25 \mathrm{~g} \mathrm{~L}^{-1}\right)$ by precipitation using solutions of varying $\mathrm{NaOH}$ equivalents and $\mathrm{O}: \mathrm{A}$ ratios, and the final $\mathrm{pH}$ of the $\mathrm{NaOH}$ solution after stripping.

\begin{tabular}{ccccc}
\hline $\begin{array}{c}\mathrm{NaOH} \\
\text { equivalents }\end{array}$ & O:A ratio & $\begin{array}{c}\mathrm{NaOH} \text { concentration } \\
\left(\mathrm{mol} \mathrm{L}^{-1}\right)\end{array}$ & $\begin{array}{c}\text { In stripping efficiency } \\
(\%)\end{array}$ & $\begin{array}{c}\mathrm{pH} \text { aqueous phase } \\
\text { after stripping }\end{array}$ \\
\hline 3 & 1 & 0.64 & 60 & 10.9 \\
4 & 1 & 0.86 & 65 & 12.0 \\
5 & 1 & 1.07 & 88 & 12.2 \\
& 0.5 & 0.54 & 99 & 11.6 \\
& 0.25 & 0.27 & 100 & 11.4 \\
6 & 1 & 1.28 & 100 & 12.3 \\
& 0.5 & 0.64 & 100 & 11.9 \\
& 0.25 & 0.32 & 100 & 11.7 \\
\hline
\end{tabular}

Due to the low solubility of $\ln (\mathrm{OH})_{3}$ in water $\left(\mathrm{K}_{\mathrm{sp}}=10^{-33}\right)$ it was expected that three equivalents should suffice to completely strip indium from the IL. ${ }^{46}$ However, up to five equivalents and an O:A ratio of 0.5 or lower were required. This last observation is surprising since a lower aqueous phase volume should only decrease the solubility of the $\operatorname{In}(\mathrm{OH})_{3}$. A possible explanation might be the transfer of the $\mathrm{NaBr}$ to the aqueous phase, which may be hampered when using smaller volumes of water. When using six equivalents of $\mathrm{NaOH}$, this trend is not observed and indium is fully precipitated for all O:A ratios. The final $\mathrm{pH}$ of the $\mathrm{NaOH}$ solution after stripping appears not to be a crucial factor for the precipitation, as these values are not higher for solutions with $100 \%$ precipitation compared to solutions with lower yields.

\section{Mechanistic study}

A mechanistic study was performed to understand the differences in stripping behavior of the different metals. Starting from the extraction equation (4) with constant $\mathrm{K}_{\mathrm{Eq}}$, and its formula (6); and after inserting the distribution ratio (5), we obtain equation (7). This equation is often used to perform a 'slope analysis', an experiment to determine the coordination sphere of extracted metal ions.

$$
\left[\mathrm{P}_{44410}\right]_{x}\left[\mathrm{MBr}_{\mathrm{n}+\mathrm{x}}\right] \leftrightarrows \mathrm{M}_{\mathrm{aq}}^{\mathrm{n+}}+\mathrm{nBr} r_{\mathrm{aq}}^{-}+\mathrm{x}\left[\mathrm{P}_{44410}\right][\mathrm{Br}]
$$




$$
\begin{gathered}
D=\frac{\left\{\left[\mathrm{P}_{44410}\right]_{\mathrm{x}}\left[\mathrm{MBr}_{\mathrm{n}+\mathrm{x}}\right]\right\}}{\left\{\mathrm{M}_{\mathrm{aq}}^{\mathrm{n}+}\right\}} \\
\mathrm{K}_{\mathrm{eq}}=\frac{\left\{\mathrm{P}_{44410} \mathrm{Br}\right\}^{\mathrm{x}}\{\mathrm{Br}\}^{\mathrm{n}}\left\{\mathrm{M}_{\mathrm{aq}}^{\mathrm{n}+}\right\}}{\left\{\left[\mathrm{P}_{44410}\right]_{\mathrm{x}}\left[\mathrm{MBr} \mathrm{n}_{\mathrm{x}}\right]\right\}}=\frac{\left\{\mathrm{P}_{44410} \mathrm{Br}\right\}^{\mathrm{x}}\{\mathrm{Br}\}^{\mathrm{n}}}{D} \\
\log D=\mathrm{n} \log \left\{\mathrm{Br}^{-}\right\}+\mathrm{x} \log \left\{\left[\mathrm{P}_{44410}\right][\mathrm{Br}]\right\}-\log \mathrm{K}_{\mathrm{eq}}
\end{gathered}
$$

The data in Figure 5 and Figure 6 can be used to perform a slope analysis, as they contain the stripping of arsenic and gallium as a function of the bromide concentration. However, when performing a slope analysis, the ionic strength of the solutions needs to be constant. So with varying concentration of $\mathrm{NaBr}$, other salts have to be added to keep a constant ionic strength. This is impossible as almost all salts influence the stripping of either arsenic, gallium or indium (Figure 3). Another approach was opted by varying the IL concentration in a toluene phase. The equilibrium was studied by extracting the metals from a constant aqueous bromide solution to the organic phase, instead of stripping from the loaded IL by varying salt concentrations. Depending on the speciation of the metals, the charge of the metal bromide complex would need a certain number of phosphonium counter ions. Therefore, the IL content in the organic phase will influence the stripping of the metals to this organic phase. The initial aqueous solution was constant at $2 \mathrm{~mol} \mathrm{~L}^{-1}$ bromide and $0.5 \mathrm{~g} \mathrm{~L}^{-1} \mathrm{Ga}(\mathrm{III}), \mathrm{As}(\mathrm{V})$ or $\mathrm{In}(\mathrm{III})$. The resulting log-log plot and statistical analysis are shown in Figure S6. The indium concentration in the water phase could not be determined as its concentration was below the detection limit of the equipment used. The resulting slope for gallium, when rounded up to an integer number, is equal to 1 , implying that one IL molecule is involved in the stripping. This implies that gallium is extracted as $\left[\mathrm{P}_{44410}\right]\left[\mathrm{GaBr}_{4}\right]$. Arsenic on the other hand, has a slope of -0.56 , combined with the high scattering of the data this implies that there seems to be no correlation between the arsenic stripping and the IL concentration in the toluene phase. This means that no bromide anions are released into the organic phase upon stripping, so the arsenic is not stripped as a charged bromide complex. What is happening is that the arsenic, after leaching and 
contact with the aqueous phase, gets hydrolyzed into arsenic oxyacid. ${ }^{47,48}$ This was confirmed by Raman spectroscopy when measuring the $\mathrm{NaBr}$ solution before and after stripping (Figure $\mathrm{S} 7$ and $\mathrm{S} 8$ ). The $\mathrm{pH}$ of the $\mathrm{NaBr}$ solution after stripping was 6.2 , at this acidity the peak in the Raman spectrum (Figure S8) corresponds to the As-OH stretch in $\mathrm{H}_{2} \mathrm{AsO}_{4}{ }^{-}{ }^{-49,50}$ This clarifies the observation that the arsenic stripping is not greatly influenced by changing the bromide concentration in the stripping solution. Besides that, this is confirmation that the formation of arsine $\left(\mathrm{AsH}_{3}\right)$ is avoided.

\section{Conceptual flowsheet}

Figure 7 contains a conceptual flowsheet, based on the experiments discussed above, for the recovery of indium, gallium and arsenic from GaAs and InAs semiconductors in a process using a nonvolatile tribromide IL. The process summarized here consists of two steps: (1) leaching of the semiconductors in the tribromide IL and (2) selective stripping to separate the metal ions with > 99\% yield. The stripping consists of several stages. First, a $4 \mathrm{~mol} \mathrm{~L}^{-1} \mathrm{NaBr}$ solution with an O:A ratio of 2 is used to remove arsenic in 3 stages to obtain $\mathrm{H}_{2} \mathrm{AsO}_{4}{ }^{-}$in the arsenic concentrate. Second, gallium is removed by washing 3 times with pure water $(\mathrm{O}: \mathrm{A}$ ratio $=1)$ to obtain the gallium concentrate. Thirdly, indium is collected as $\ln (\mathrm{OH})_{3}$ via precipitation stripping, by contacting the IL phase with a aqueous solution containing 5 equivalents of $\mathrm{NaOH}$. When all the metals (As, Ga and In) are removed, the only contaminants possibly left in the IL are $\mathrm{NaBr}$ and $\mathrm{NaOH}$, but these compounds could be easily removed by washing the IL with water. This would result in a pure, but water-saturated IL. Both the phosphonium cation and tribromide anion (Figure S4) are not damaged by water, and could therefore be reused. The reacted tribromide anion could be regenerated by addition of molecular bromine. The effect of water on this step was not within the scope of this research, but if required, the IL could be dried prior to the regeneration. 


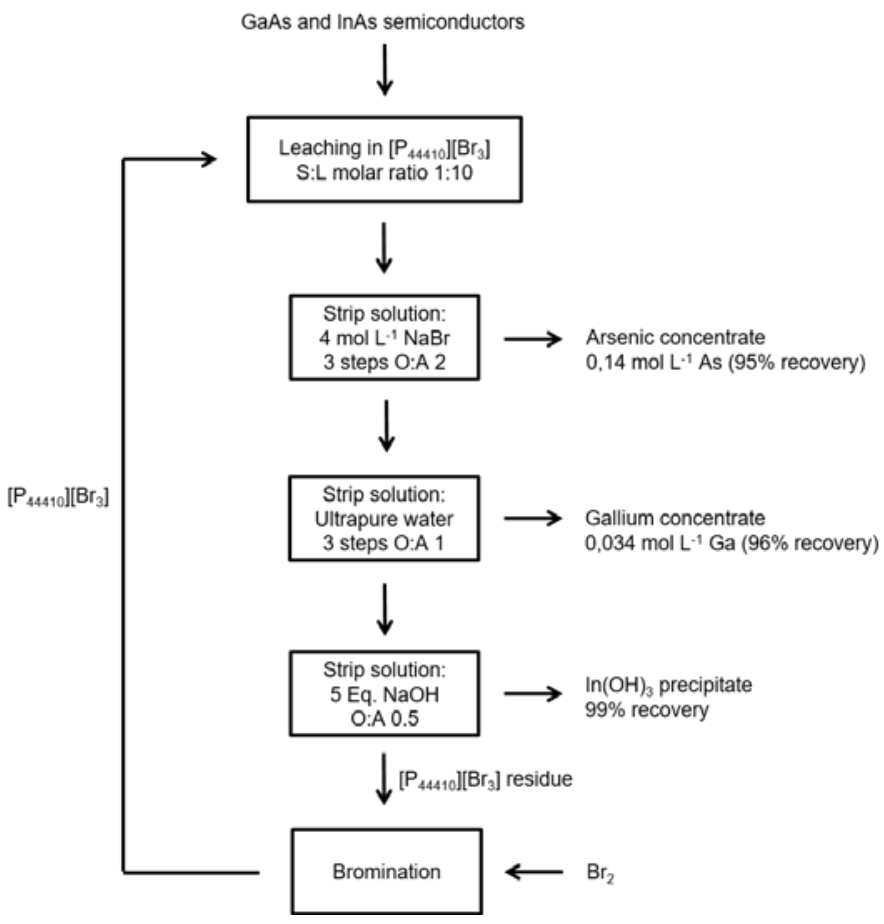

Figure 7: Conceptual flowsheet for the leaching and separation of arsenic, gallium and indium from GaAs and InAs semiconductors.

In order to get insight in the physical properties of the IL and to provide useful data for process development, the viscosity and density of the IL were measured at various points in the process. The pure tribromide IL, an InAs leachate and the completely stripped water-saturated IL were measured at different temperatures. The data are summarized in the ESI (Figure S9 and S10). As expected, both the viscosity and density increase when loading the IL with metals. The increase in viscosity can be explained by the higher charge caused by the metal bromide anions and subsequent increased interaction between the ions. When the IL is saturated with water, the viscosity and density decrease. Important to mention is that the density of the IL remains higher than $1.15 \mathrm{~g} / \mathrm{cm}^{3}$. This is important as a density drop might cause phase inversion with aqueous phases, which causes problems for continuous processes. 


\section{Leaching of LEDs}

After the design of the conceptual flowsheet (Figure 7) for the recycling of semiconductors, the procedure was tested on real LEDs. Due to the difficulties in obtaining LEDs with one single type of semiconductor, only LEDs containing GaAs were purchased, emitting infrared (IR) light with a wavelength of $950 \mathrm{~nm}$. This implies that only the first three steps of the flowsheet in Figure 7 could be tested on real LEDs.

The LEDs were divided in three fractions: a coarse plastic, fine plastic and metallic fraction, via disc milling and separation (Figure S11 and S12). The different fractions were leached in $\left[\mathrm{P}_{44410}\right]\left[\mathrm{Br}_{3}\right]$ and the metal content was measured using ICP-OES, the results are displayed in Table 2. Besides the values of gallium and arsenic, the other metals present in the leachates are listed as well. It is immediately clear that the targeted metals, arsenic and gallium, are only present in small amounts compared to the other metals, which were not investigated in the synthetic samples. Especially the iron content was surprisingly high: even after the removal of the electrodes sticking out of the plastic, the part of the electrode that remains embedded in the plastic is enough to make iron the main metal in the electrode fraction. However, by magnetic separation, the remainder of the electrodes in the milled samples could be removed easily. The metallic fraction was discarded due to this easy removal of the electrodes and the low gallium and arsenic content. The fine plastic fraction $(1.73 \mathrm{~g})$ was leached in $6.03 \mathrm{~g}$ of $\left[\mathrm{P}_{44410}\right]\left[\mathrm{Br}_{3}\right]$ as described in the experimental section. Afterwards, the IL underwent the stripping procedures described in the flowsheet (Figure 7). All aqueous solutions were analyzed using ICP-OES (Table 3). One important remark is that due to the low measured concentration of gallium with respect to arsenic in the stripping solutions is due to the usage of a higher O:A ratio in the stripping of gallium. Due the fact that twice the stripping volume was used when stripping with pure water, the concentration drops by a factor of 2 . 
Table 2: metal content (ppm) of leachates from different fractions of the disc milled LEDs.

\begin{tabular}{c|ccccccccc} 
& $\mathrm{As}$ & $\mathrm{Ga}$ & $\mathrm{Al}$ & $\mathrm{Au}$ & $\mathrm{Cu}$ & $\mathrm{Fe}$ & $\mathrm{Pb}$ & $\mathrm{Sn}$ & $\mathrm{Ni}$ \\
\hline Electrodes & 24 & 44 & 141 & 124 & 2531 & 76864 & 66 & 189 & 442 \\
Fine plastic & 53 & 109 & 53 & 142 & 63 & 238 & 73 & 28 & 40 \\
Coarse plastic & 48 & 58 & 41 & 107 & 38 & 99 & 76 & 18 & 38
\end{tabular}

Table 3: Metal concentrations (ppm) of strip solutions from the fine plastic fraction leachates in $\left[\mathrm{P}_{44410}\right]\left[\mathrm{Br}_{3}\right]$.

\begin{tabular}{c|cccccccccc} 
& $\begin{array}{c}\mathrm{O}: \mathrm{A} \\
\text { ratio }\end{array}$ & $\mathrm{As}$ & $\mathrm{Ga}$ & $\mathrm{Al}$ & $\mathrm{Au}$ & $\mathrm{Cu}$ & $\mathrm{Fe}$ & $\mathrm{Pb}$ & $\mathrm{Sn}$ & $\mathrm{Ni}$ \\
\hline $\begin{array}{c}4 \mathrm{~mol} \mathrm{~L}^{-1} \\
\mathrm{NaBr}\end{array}$ & 2 & 891 & 3.6 & 18 & 0.3 & 6.9 & 2.2 & 37 & 0.7 & 28 \\
$\begin{array}{c}4 \mathrm{~mol} \mathrm{~L}^{-1} \\
\mathrm{NaBr}\end{array}$ & 2 & 63 & 4.4 & 7.1 & 0.1 & 6.9 & 0.6 & 22 & 0.4 & 1.9 \\
$4 \mathrm{~mol} \mathrm{~L}^{-1}$ & 2 & 11 & 5.7 & 6.8 & 0.2 & 6.6 & 0.6 & 19 & 0.4 & 1.0 \\
$\begin{array}{c}\mathrm{NaBr} \\
\text { Pure }\end{array}$ & 1 & 3.3 & 342 & 5.7 & 31 & 65 & 195 & 1.9 & 0.0 & 0.5 \\
$\begin{array}{c}\text { water } \\
\text { Pure } \\
\text { water }\end{array}$ & 1 & 0.6 & 31 & 2.4 & 0.8 & 6.0 & 28 & 0.4 & 0.0 & 0.0
\end{tabular}

Looking at the concentrations of arsenic and gallium in Table 3, it appears that the stripping procedure proposed in Figure 7 works not only for pure semiconductor material, but also for semiconductors isolated from real LEDs. The other metals present are contaminants of the strip solutions, but the removal of these metals was outside the scope of this work, which was to investigate whether stripping of gallium and arsenic was different for real LEDs compared to pure semiconductor material. When looking only at the columns with the analysis data for arsenic and gallium, the results seem on par with the results obtained for pure semiconductors: $99.6 \%$ of the stripped arsenic resided in the $\mathrm{NaBr}$ solutions, and $96.5 \%$ of the stripped gallium was present in the pure water solutions.

\section{Conclusion}

The recycling of gallium, indium and arsenic from GaAs, GaN and InAs semiconductors using a tribromide ionic liquid was investigated. The solubility of a series of tribromide ILs with $n$-dodecane and 
water was examined and an IL was selected for the leaching of the semiconductors. The arsenic-based semiconductors, GaAs and InAs, could be leached in nonaqueous conditions in the nonvolatile IL, $\left[\mathrm{P}_{44410}\right]\left[\mathrm{Br}_{3}\right]$, avoiding arsine formation. GaN could not be dissolved. A series of experiments was performed in order to investigate a selective stripping procedure for gallium, indium and arsenic from a leachate of GaAs and InAs semiconductors. Stripping using organic extractants in an $n$-dodecane phase was investigated, but proved to be not selective and suffered from low stripping efficiencies. Selective stripping could be achieved by using aqueous stripping liquors. Contacting the IL leachate with $\mathrm{NaBr}$ solutions converted the arsenic to arsenic acid, not arsine, stripping it completely. Gallium was left in the IL, which could be removed by washing with pure water. The indium remained in the IL and was precipitated as $\operatorname{In}(\mathrm{OH})_{3}$ by washing with a $\mathrm{NaOH}$ solution. This way, the three metals, arsenic, gallium and indium could be selectively stripped from the IL phase. The leaching and stripping procedures were tested on real LED samples. This process could be beneficial for safer leaching of arsenic-containing compounds, avoiding arsine formation, and recovery of critical metals from LEDs.

\section{Associated content}

\section{Supporting information}

Supporting Information (SI) available: chemicals, techniques and sample preparations, IL synthesis, solubility study, mechanistic study, thermophysical data and physical treatments of LEDs.

\section{Author information}

Corresponding author:

Prof. Koen Binnemans E-mail: Koen.Binnemans@kuleuven.be Phone: +3216327446. 
ORCID

- Arne Van den Bossche: 0000-0001-6388-1851

- Willem Vereycken: 0000-0002-0355-2009

- Tom Vander Hoogerstraete: $\quad$ 0000-0002-1110-699X

- Wim Dehaen: 0000-0002-9597-0629

- Koen Binnemans: 0000-0003-4768-3606

Notes

The authors declare no competing financial interest.

\section{Acknowledgements}

The authors acknowledge the KU Leuven (C32/17/011), as well as the Research Foundation Flanders (FWO) for a PhD grant to Arne Van den Bossche (1S04216N) and a postdoc grant to Tom Vander Hoogerstraete (12J4116N). 


\section{References}

(1) Chitnis, D.; Thejo kalyani, N.; Swart, H. C.; Dhoble, S. J. Escalating Opportunities in the Field of Lighting. Renew. Sustain. Energy Rev. 2016, 64, 727-748.

https://doi.org/10.1016/j.rser.2016.06.041.

(2) Sanderson, S. W.; Simons, K. L. Light Emitting Diodes and the Lighting Revolution: The Emergence of a Solid-State Lighting Industry. Res. Policy 2014, 43 (10), 1730-1746.

https://doi.org/10.1016/j.respol.2014.07.011.

(3) Moskalyk, R. R. Gallium: The Backbone of the Electronics Industry. Miner. Eng. 2003, 16 (10), 921-929. https://doi.org/10.1016/j.mineng.2003.08.003.

(4) Mizanur Rahman, S. M.; Kim, J.; Lerondel, G.; Bouzidi, Y.; Nomenyo, K.; Clerget, L. Missing Research Focus in End-of-Life Management of Light-Emitting Diode (LED) Lamps. Resour. Conserv. Recycl. 2017, 127, 256-258. https://doi.org/10.1016/j.resconrec.2017.04.013.

(5) Nagy, S.; Bokányi, L.; Gombkötő, I.; Magyar, T. Recycling of Gallium from End-of-Life Light Emitting Diodes. Arch. Metall. Mater. 2017, 62 (2), 1161-1166. https://doi.org/10.1515/amm2017-0170.

(6) Zhang, X.; Yin, G.; Hu, Z. Extraction and Separation of Gallium, Indium and Thallium with Several Carboxylic Acids from Chloride Media. Talanta 2003, 59 (5), 905-912. https://doi.org/10.1016/S0039-9140(02)00646-X.

(7) Zhan, L.; Li, J.; Xie, B.; Xu, Z. Recycling Arsenic from Gallium Arsenide Scraps through Sulfurizing Thermal Treatment. ACS Sustain. Chem. Eng. 2017, 5 (4), 3179-3185. https://doi.org/10.1021/acssuschemeng.6b02962.

(8) Swain, B.; Mishra, C.; Kang, L.; Park, K.-S.; Lee, C. G.; Hong, H. S. Recycling Process for Recovery of Gallium from GaN an E-Waste of LED Industry through Ball Milling, Annealing and Leaching. Environ. Res. 2015, 138, 401-408. https://doi.org/10.1016/j.envres.2015.02.027.

(9) Hu, S.-H.; Xie, M.-Y.; Hsieh, Y.-M.; Liou, Y.-S.; Chen, W.-S. Resource Recycling of Gallium Arsenide Scrap Using Leaching-Selective Precipitation. Environ. Prog. Sustain. Energy 2015, 34 (2), 471475. https://doi.org/10.1002/ep.12019.

(10) Pakulska, D.; Czerczak, S. Hazardous Effects of Arsine: A Short Review. Int. J. Occup. Med. Environ. Health 2006, 19 (1), 36-44. https://doi.org/10.2478/v10001-006-0003-z.

(11) Scott, N.; Carter, D. E.; Fernando, Q. Reaction of Gallium Arsenide with Concentrated Acids: Formation of Arsine. Am. Ind. Hyg. Assoc. J. 1989, 50 (7), 379-381. https://doi.org/10.1080/15298668991374831.

(12) Binnemans, K.; Jones, P. T. Solvometallurgy: An Emerging Branch of Extractive Metallurgy. J. Sustain. Metall. 2017, 3 (3), 570-600. https://doi.org/10.1007/s40831-017-0128-2.

(13) Abbott, A. P.; Frisch, G.; Gurman, S. J.; Hillman, A. R.; Hartley, J.; Holyoak, F.; Ryder, K. S. lonometallurgy: Designer Redox Properties for Metal Processing. Chem. Commun. 2011, 47 (36), 10031-10033. https://doi.org/10.1039/C1CC13616J.

(14) Welton, T. Room-Temperature Ionic Liquids. Solvents for Synthesis and Catalysis. Chem. Rev. 1999, 99 (8), 2071-2084. https://doi.org/10.1021/cr980032t.

(15) Plechkova, N. V.; Seddon, K. R. Applications of lonic Liquids in the Chemical Industry. Chem. Soc. Rev. 2007, 37 (1), 123-150. https://doi.org/10.1039/B006677J.

(16) Chubb, J. N.; Lagos, P.; Lienlaf, J. Electrostatic Safety during the Solvent Extraction of Copper. J. Electrost. 2005, 63 (2), 119-127. https://doi.org/10.1016/j.elstat.2004.09.002.

(17) Fox, D. M.; Awad, W. H.; Gilman, J. W.; Maupin, P. H.; Long, H. C. D.; Trulove, P. C. Flammability, Thermal Stability, and Phase Change Characteristics of Several Trialkylimidazolium Salts. Green Chem. 2003, 5 (6), 724-727. https://doi.org/10.1039/B308444B. 
(18) Haller, H.; Riedel, S. Recent Discoveries of Polyhalogen Anions - from Bromine to Fluorine. Z. Für Anorg. Allg. Chem. 2014, 640 (7), 1281-1291. https://doi.org/10.1002/zaac.201400085.

(19) Cristiano, R.; Ma, K.; Pottanat, G.; Weiss, R. G. Tetraalkylphosphonium Trihalides. Room Temperature Ionic Liquids As Halogenation Reagents. J. Org. Chem. 2009, 74 (23), 9027-9033. https://doi.org/10.1021/jo901735h.

(20) Dean, P. M.; Clare, B. R.; Armel, V.; Pringle, J. M.; Forsyth, C. M.; Forsyth, M.; MacFarlane, D. R. Structural Characterization of Novel Ionic Salts Incorporating Trihalide Anions. Aust. J. Chem. 2009, 62 (4), 334-340.

(21) Barnea, Z.; Sachs, T.; Chidambaram, M.; Sasson, Y. A Novel Oxidative Method for the Absorption of $\mathrm{HgO}$ from Flue Gas of Coal Fired Power Plants Using Task Specific Ionic Liquid Scrubber. J. Hazard. Mater. 2013, 244-245, 495-500. https://doi.org/10.1016/j.jhazmat.2012.10.067.

(22) Rogers, R. D.; Holbrey, J. D. Ionic Liquid Solvents of Perhalide Type for Metals and Metal Compounds. US20120090430 A1, April 19, 2012.

(23) Dadgar, A. Refractory Concentrate Gold Leaching: Cyanide vs. Bromine. JOM 1989, 41 (12), 3741. https://doi.org/10.1007/BF03220846.

(24) Lin, W. Organic Aqua Regia: Discovery, Fundamentals, and Potential Applications. In Noble Metals; Su, Y.-H., Ed.; InTech: Rijeka, 2012.

(25) Gustafsson, A. M. K.; Steenari, B.-M.; Ekberg, C. Evaluation of High-Temperature Chlorination as a Process for Separation of Copper, Indium and Gallium from CIGS Solar Cell Waste Materials. Sep. Sci. Technol. 2015, 50 (1), 1-9. https://doi.org/10.1080/01496395.2014.949350.

(26) Strubbe, K.; Gomes, W. P. Bromine-Methanol as an Etchant for Semiconductors: A Fundamental Study on GaP I . Etching Behavior of N- and P-Type. J. Electrochem. Soc. 1993, 140 (11), 32943300. https://doi.org/10.1149/1.2221026.

(27) Ubaldini, S.; Fornari, P.; Massidda, R.; Abbruzzese, C. An Innovative Thiourea Gold Leaching Process. Hydrometallurgy 1998, 48 (1), 113-124. https://doi.org/10.1016/S0304-386X(97)000765.

(28) Borikar, S. P.; Daniel, T.; Paul, V. An Efficient, Rapid, and Regioselective Bromination of Anilines and Phenols with 1-Butyl-3-Methylpyridinium Tribromide as a New Reagent/Solvent under Mild Conditions. Tetrahedron Lett. 2009, 50 (9), 1007-1009.

https://doi.org/10.1016/j.tetlet.2008.12.053.

(29) Chiappe, C.; Pieraccini, D. Kinetic Study of the Addition of Trihalides to Unsaturated Compounds in Ionic Liquids. Evidence of a Remarkable Solvent Effect in the Reaction of $\mathrm{ICl} 2-$. J. Org. Chem. 2004, 69 (18), 6059-6064. https://doi.org/10.1021/jo049318q.

(30) Zelikman, V. M.; Tyurin, V. S.; Smirnov, V. V.; Zyk, N. V. Quaternary Ammonium Polychlorides as Efficient Reagents for Chlorination of Unsaturated Compounds. Russ. Chem. Bull. 1998, 47 (8), 1541-1546. https://doi.org/10.1007/BF02495606.

(31) Bortolini, O.; Bottai, M.; Chiappe, C.; Conte, V.; Pieraccini, D. Trihalide-Based Ionic Liquids. Reagent-Solvents for Stereoselective lodination of Alkenes and Alkynes. Green Chem. 2002, 4 (6), 621-627. https://doi.org/10.1039/B209436N.

(32) Williams, T.; Krudener, J.; McFarland, J. Use of Pyridinium Bromide Perbromide as an Analytical Reagent. Anal. Chim. Acta 1964, 30, 155-162. https://doi.org/10.1016/S0003-2670(00)88703-6.

(33) Van den Bossche, A.; De Witte, E.; Dehaen, W.; Binnemans, K. Trihalide Ionic Liquids as NonVolatile Oxidizing Solvents for Metals. Green Chem. 2018, 20 (14), 3327-3338. https://doi.org/10.1039/C8GC01061G.

(34) Li, X.; Van den Bossche, A.; Vander Hoogerstraete, T.; Binnemans, K. Ionic Liquids with Trichloride Anions for Oxidative Dissolution of Metals and Alloys. Chem. Commun. 2018, 54 (5), 475-478. https://doi.org/10.1039/C7CC08645H. 
(35) Li, X.; Li, Z.; Orefice, M.; Binnemans, K. Metal Recovery from Spent Samarium-Cobalt Magnets Using a Trichloride Ionic Liquid. ACS Sustain. Chem. Eng. 2019, 7 (2), 2578-2584.

https://doi.org/10.1021/acssuschemeng.8b05604.

(36) May, B.; Lexow, M.; Taccardi, N.; Steinrück, H.-P.; Maier, F. Reactions of a Polyhalide lonic Liquid with Copper, Silver, and Gold. ChemistryOpen 2019, 8 (1), 15-22. https://doi.org/10.1002/open.201800149.

(37) Gupta, B.; Mudhar, N.; Tandon, S. N. Extraction and Separation of Gallium Using Cyanex 301: Its Recovery from Bayer's Liquor. Ind. Eng. Chem. Res. 2005, 44 (6), 1922-1927. https://doi.org/10.1021/ie049730w.

(38) Gupta, B.; Mudhar, N.; Begum, Z.; Singh, I. Extraction and Recovery of Ga(III) from Waste Material Using Cyanex 923. Hydrometallurgy 2007, 87 (1), 18-26. https://doi.org/10.1016/j.hydromet.2007.01.001.

(39) Lee, M. S.; Ahn, J. G.; Lee, E. C. Solvent Extraction Separation of Indium and Gallium from Sulphate Solutions Using D2EHPA. Hydrometallurgy 2002, 63 (3), 269-276. https://doi.org/10.1016/S0304-386X(02)00004-X.

(40) Rais-Zadeh, M.; Gokhale, V. J.; Ansari, A.; Faucher, M.; Théron, D.; Cordier, Y.; Buchaillot, L. Gallium Nitride as an Electromechanical Material. J. Microelectromechanical Syst. 2014, 23 (6), 1252-1271. https://doi.org/10.1109/JMEMS.2014.2352617.

(41) Pearton, S. J.; Zolper, J. C.; Shul, R. J.; Ren, F. GaN: Processing, Defects, and Devices. J. Appl. Phys. 1999, 86 (1), 1-78. https://doi.org/10.1063/1.371145.

(42) Harrison, W. A. Electronic Structure and the Properties of Solids: The Physics of the Chemical Bond; New York, 2012.

(43) Deferm, C.; Van de Voorde, M.; Luyten, J.; Oosterhof, H.; Fransaer, J.; Binnemans, K. Purification of Indium by Solvent Extraction with Undiluted Ionic Liquids. Green Chem. 2016, 18 (14), 41164127. https://doi.org/10.1039/C6GC00586A.

(44) Landini, D.; Maia, A.; Rampoldi, A. Stability of Quaternary Onium Salts under Phase-Transfer Conditions in the Presence of Aqueous Alkaline Solutions. J. Org. Chem. 1986, 51 (16), 31873191. https://doi.org/10.1021/jo00366a022.

(45) Tseng, M.-C.; Kan, H.-C.; Chu, Y.-H. Reactivity of Trihexyl(Tetradecyl)Phosphonium Chloride, a Room-Temperature Phosphonium lonic Liquid. Tetrahedron Lett. 2007, 48 (52), 9085-9089. https://doi.org/10.1016/j.tetlet.2007.10.131.

(46) Busev, A. I. The Analytical Chemistry of Indium - 1st Edition; Elsevier: Frankfurt, 2013.

(47) Lu, P.; Zhu, C. Arsenic Eh-PH Diagrams at $25^{\circ} \mathrm{C}$ and 1 Bar. Environ. Earth Sci. 2011, 62 (8), 16731683. https://doi.org/10.1007/s12665-010-0652-x.

(48) Mähler, J.; Persson, I.; Herbert, R. B. Hydration of Arsenic Oxyacid Species. Dalton Trans. 2013, 42 (5), 1364-1377. https://doi.org/10.1039/C2DT31906C.

(49) Goldberg, S.; Johnston, C. T. Mechanisms of Arsenic Adsorption on Amorphous Oxides Evaluated Using Macroscopic Measurements, Vibrational Spectroscopy, and Surface Complexation Modeling. J. Colloid Interface Sci. 2001, 234 (1), 204-216. https://doi.org/10.1006/jcis.2000.7295.

(50) Tossell, J. A. Theoretical Studies on Arsenic Oxide and Hydroxide Species in Minerals and in Aqueous Solution. Geochim. Cosmochim. Acta 1997, 61 (8), 1613-1623. https://doi.org/10.1016/S0016-7037(97)00030-6. 


\section{TOC graphic}

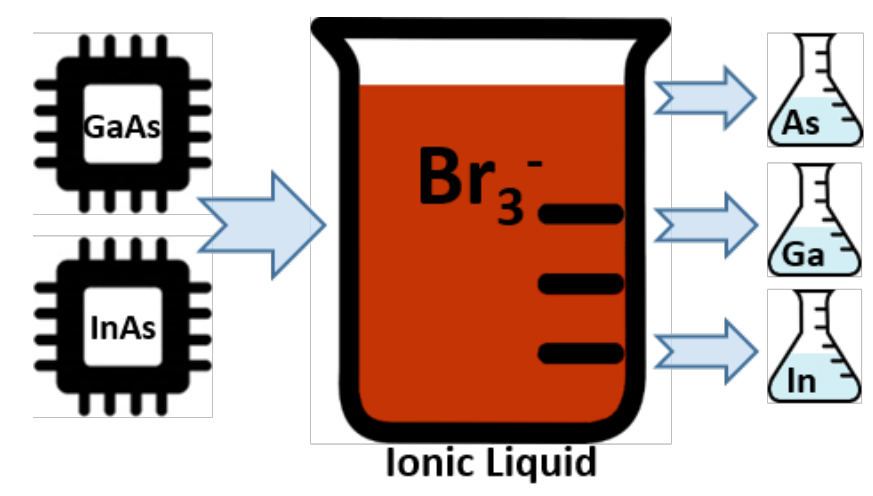

\section{Synopsis}

The dissolution and recycling of arsenic containing semiconductors in nonaqueous and nonvolatile ionic liquids prevents the formation of the toxic and volatile arsine. 